Conclusion: Our clinical trial offers preliminary evidence on the superiority of Kinesio-Taping in the treatment chronic back pain compared to placebo concerning the reduction of pain and disability. Thus, it can be used as a complementary method in chronic non-specific low back pain.

Table 2. Primary and secondary outcomes in the Kinesio-Taping and placebo group.

\begin{tabular}{|c|c|c|c|c|c|c|c|c|c|}
\hline & \multicolumn{4}{|c|}{ Taping groupe $(\mathrm{n}=22)$} & \multicolumn{4}{|c|}{ Placebo groupe $(\mathrm{n}=24)$} & \multirow{2}{*}{ ANCOVA } \\
\hline & Baseline & Day 12 & 4 weeks & $p$ value & Baseline & Day 12 & 4 weeks & $p$ value & \\
\hline ODI & $36 \pm 18,82$ & $24 \pm 19,83$ & $24 \pm 19,32$ & $<0,001$ & $31 \pm 12,65$ & $28 \pm 13,32$ & $29 \pm 13,24$ & 0,03 & $<0,001$ \\
\hline VAS of pain & $7 \pm 1,3$ & $3,9 \pm 2,2$ & $4,6 \pm 2,2$ & $<0,001$ & $6,5 \pm 1,2$ & $5,5 \pm 2,2$ & $5,7 \pm 2,2$ & 0,008 & $<0,001$ \\
\hline $\begin{array}{l}\text { VAS of } \\
\text { functional } \\
\text { disability }\end{array}$ & $6,7 \pm 1,5$ & $4 \pm 2,8$ & $4,4 \pm 2,5$ & $<0,001$ & $5,9 \pm 2,3$ & $5,2 \pm 2,2$ & $5,3 \pm 2,2$ & 0,003 & $<0,001$ \\
\hline $\begin{array}{l}\text { Rolland } \\
\text { Morris }\end{array}$ & $7,4 \pm 4,6$ & $5,2 \pm 4,7$ & $5,3 \pm 4,6$ & $<0,001$ & $8,4 \pm 4,8$ & $7,6 \pm 4,2$ & $7,3 \pm 4,1$ & 0,05 & 0,06 \\
\hline
\end{tabular}

Disclosure of Interests: None declared

DOI: 10.1136/annrheumdis-2020-eular.2979

\section{THU0567 HIP ABDUCTORS STRENGTH AND TRUNK, PELVIS, HIP AND KNEE FRONTAL PLANE KINEMATICS ANALYSIS DURING SINGLE-LEG SQUAT IN INDIVIDUALS WITH AND WITHOUT PATELLOFEMORAL OSTEOARTHRITIS}

C. Carvalho $^{1}$, G. Keppe Pisani ${ }^{1}$, A. Felipe Martinez ${ }^{1}$, L. Mancini ${ }^{1}$, F. Viadanna Serrão ${ }^{1}$, P. Regina Mendes Da Silva Serrão ${ }^{1} .{ }^{1}$ Federal University of São Carlos, Physical Therapy, São Carlos, Brazil

Background: Previous studies have observed that individuals with patellofemoral pain (PFP) have decreased hip abduction torque, as well as increased hip adduction and knee abduction during activities with uniltateral weight bearing ${ }^{1,2}$ Considering that, a significant number of patients with patellofemoral osteoarthritis (PFOA) have a previous history of $\mathrm{PFP}^{3}$, it is speculated that the mechanical causes of PFP and PFOA may be similar. However, although alterations in hip muscle strength and lower limb kinematics during various functional activities have been reported in patients with PFP, they have not been explored in subjects with PFOA.

Objectives: The objectives of this study were to compare the hip eccentric abductors torque and the trunk, pelvis, hip, and knee frontal plane kinematics in subjects with and without PFOA isolated during the single-leg squat.

Methods: This is a cross-sectional study. The volunteers were divided into two groups: control group (CG - healthy individuals) and PFOA group (PFOAG - individuals with PFOA grade II or III). Eccentric peak torque of the hip abductors was evaluated using an isokinetic dynamometer Biodex Multi-Joint System 3, at angular speed of $30 \%$ s. Trunk, pelvis, hip and knee kinematics were recorded during the single-leg squat using a 6-camera, 3-dimensional motion-analysis system (Vicon Motion Systems, Nexus System 2.1.1 and 3D Motion Monitor). The t-test Student was used to compare the variables between the groups. The significance level was set at $5 \%$ for all analyses ( $\mathrm{p} \leq 0.05$ ).

Results: The CG was composed by 12 participants (41.7\% women). PFOA had 9 participants $(44.4 \%$ women). Age $(p=0.1)$, height $(p=0.9)$ and body mass $(p=0.2$ ) showed homogeneity between groups. Regardind body mass index, the OAPFG showed higher values $(p=0.02)$. PFOAG showed greater increased

Table 1 - Values of joint angles during single-leg squatting and hip abductors torque (normalized by body mass) in PFOA and healthy individuals

\begin{tabular}{lccc}
\hline & PFOAG & CG & $p$ value \\
\hline Contralateral trunk lean $\left(^{\circ}\right)$ & $4.7 \pm 1.3$ & $4.8 \pm 1.1$ & 0.94 \\
Contralateral pelvic elevation $\left(^{\circ}\right)$ & $1.4 \pm 1.2$ & $2.6 \pm 1.0$ & 0.45 \\
Hip adduction $\left({ }^{\circ}\right)$ & $14.9 \pm 2.2$ & $8.9 \pm 1.6$ & $0.05^{*}$ \\
Knee abduction $\left({ }^{\circ}\right.$ ) & $22.8 \pm 3.8$ & $19.4 \pm 3.3$ & 0.51 \\
Hip eccentric abdutor torque (Nm/kg.100) & $166.5 \pm 24.9$ & $204 \pm 27.7$ & $0.006^{*}$
\end{tabular}

PFOAG: patellofemoral osteoarthritis group; CG: control group *Statistical difference between groups hip adduction than CG $(p=0.05)$ (Table 1). However, there were no differences among groups for trunk lean, contralateral pelvic elevation and knee abduction $(p>0.05)$. PFOAG showed lower hip abductor torque compared with the CG $(\mathrm{p}=0.006)$.

Conclusion: PFOA individuals showed greater hip adduction and lower hip abductors torque than the CG. Thus, it is suggested that muscle weakness may excessively influence hip adduction. Hip adduction is the main component of the knee valgus in the frontal plane. So, excessive dynamic valgus results in an increase Q-angle and, consequently, an increase in the latera forces acting on the patella, causing greater stress on the lateral patellofemoral joint, which may contribute to disease progression. Therefore, we suggest that the hip abductor strengthening should be considered when treating individuals with PFOA.

References:

[1] Nakagawa TH, Moriya ÉTU, Maciel CD, Serrão FV. Trunk, Pelvis, Hip, and Knee Kinematics, Hip Strength, and Gluteal Muscle Activation During a Single-Leg Squat in Males and Females With and Without Patellofemoral Pain Syndrome. J Orthop Sport Phys Ther. 2012;42(6):491-501.

[2] Nakagawa TH, Moriya ÉTU, Maciel CD, Serrão FV. Frontal Plane Biomechanics in Males and Females with and without Patellofemoral Pain. Med Sci Sport Exerc. 2012;44(9):1747-1755.

[3] Utting MR, Davies G, Newman JH. Is anterior knee pain a predisposing factor to patellofemoral osteoarthritis? Knee. 2005;12(5):362-365.

Acknowledgments: São Paulo Research Foundation (FAPESP) (Grant/Award Numbers: 2017/20057-8; 2017/25959-0; 2018/10329-3).

Disclosure of Interests: None declared

DOI: 10.1136/annrheumdis-2020-eular.5924

\section{THU0568 EFFECTIVENESS OF FOOT ORTHOSIS TO PROMOTE PHYSICAL ACTIVITY FOR PATIENTS WITH CONCURRENT RHEUMATOID ARTHRITIS AND SARCOPENIA}

N. Hishikawa ${ }^{1}$, S. Toyama ${ }^{1,2,3}$, S. Ohashi ${ }^{1}$, K. Sawada ${ }^{1}$, K. Ikoma ${ }^{3}$, D. Tokunaga ${ }^{1}$, Y. Mikami ${ }^{1} .{ }^{1}$ Graduate School of Medical Science, Kyoto Prefectural University of Medicine, Department of Rehabilitation Medicine, Kyoto, Japan; ${ }^{2}$ Graduate School of Medical Science, Kyoto Prefectural University of Medicine, Department of Multidisciplinary Promote for Physical Activity, Kyoto, Japan; ${ }^{3}$ Graduate School of Medical Science, Kyoto Prefectural University of Medicine, Department of Orthopaedics, Kyoto, Japan

Background: Sarcopenia is a progressive systemic skeletal muscle disorder associated with an increased likelihood of adverse outcomes including physical disability, falls, and mortality. The muscle mass of patients with rheumatoid arthritis (RA) is lower than that of age-matched healthy individuals, and a high prevalence rate of sarcopenia has been reported ${ }^{1}$. In particular, foot deformities may increase the prevalence rate of sarcopenia because of inactivity due to foot pain on walking. Treatment with a foot orthosis (FO) can reportedly reduce pain ${ }^{2)}$; however, whether a FO can resolve inactivity and sarcopenia is unclear.

Objectives: To elucidate the effectiveness of a FO on physical activity and sarcopenia in patients with RA.

Methods: Thirty patients with RA with foot deformities were enrolled from April 2017 to December 2019. Sarcopenia was diagnosed using the algorithm of the European Working Group on Sarcopenia in Older People, and the cut-off values of the Asian Working Group for Sarcopenia were applied. We also collected the clinical variables of patients with concurrent RA and sarcopenia who continued to use a FO for 6 months. The primary outcome was physical activity determined by the International Physical Activity Questionnaire. The secondary outcomes were foot pain measured with a visual analog scale; activities of daily living (ADL) measured with the Health Assessment Questionnaire; and body mass index, body fat percentage, and the skeletal muscle mass index measured with a body composition device. The clinical variables were compared between baseline and 6 months after continuous treatment with a FO.

Results: The prevalence rate of sarcopenia was $76.6 \%(23 / 30)$, and nine patients with RA continued to use the FO for 6 months. Table 1 shows outcomes at baseline and after 6 months of treatment with a FO. The only clinical variable that showed a significant difference was foot pain Physical activities, ADL, and body compositions were maintained after 6 months. 
Table 1. Outcomes of 6-month treatment with FO

\begin{tabular}{lccc}
\hline & Baseline & 6 months & p value \\
\hline Physical activity & $132(66,594)$ & $594(396,2376)$ & 0.07 \\
IPAQ & $0(0,0)$ & $0(0,0)$ & 1.00 \\
Walking, MET-min/week & $0(0,0)$ & $0(0,0)$ & 0.32 \\
Moderate, MET-min/week & & & \\
Vigorous, MET-min/week & & & \\
Foot pain & $4.6(3.1,7.4)$ & $2.8(1.1,4.7)$ & 0.02 \\
VAS score & $1.5(1.1,2.3)$ & $1.1(0.9,1.5)$ & 0.07 \\
ADL & & & \\
HAQ & $21.4(20.7,22.7)$ & $20.7(19.3,22.1)$ & 0.89 \\
Body composition & $31.1(24.2,37.6)$ & $32.9(26.3,36.5)$ & 0.82 \\
BMI, kg/m & $5.2(4.8,5.3)$ & $5.2(5.0,5.2)$ & 0.61 \\
BFP, \% & & & \\
SMI, kg/m² & & & \\
\hline
\end{tabular}

IPAQ: International Physical Activity Questionnaire, VAS: visual analog scale, ADL: activities of daily living, HAQ: Health Assessment Questionnaire, BMI: body mass index, BFP: body fat percentage, SMI: skeletal muscle mass index

Data are presented as median (lower quartile, upper quartile)

Conclusion: The prevalence rate of sarcopenia in patients with RA with foot deformities was much higher than previous reported ${ }^{1)}$. However, 6 months of treatment with a FO not only reduced foot pain but also maintained physical activity and muscle mass. Physical therapy has recently been recommended for patients with inflammatory arthritis. physical activity and muscle mass of patients with RA and concurrent foot deformities may be increased by combining physical therapy with orthotic treatment

References:

[1] Tada M, et al. Matrix metalloprotease 3 is associated with sarcopenia in rheumatoid arthritis - results from the CHIKARA study. Int $\mathrm{J}$ Rheum Dis. 2018; 21 (11): 1962-9.

[2] Hennessy K, et al. Custom foot orthoses for rheumatoid arthritis: A systematic review. Arthritis Care Res (Hoboken). 2012; 64 (3): 311-20.

Acknowledgments: This work was supported by JSPS KAKENHI Grant Numbers JP19K11420.

Disclosure of Interests: None declared

DOI: 10.1136/annrheumdis-2020-eular.3143

\section{THU0569 PHYSICAL ACTIVITY IN AXIAL SPONDYLOARTHRITIS AND RHEUMATOID ARTHRITIS: A CROSS-SECTIONAL STUDY IN A SOUTH-EAST ASIAN COHORT}

A. Khor ${ }^{1}$, C. T. Ng ${ }^{1,2}$, W. Fong ${ }^{1,2,3} .{ }^{1}$ Singapore General Hospital, Rheumatology and Immunology, Singapore, Singapore; ${ }^{2}$ Duke-NUS Medical School, Singapore, Singapore; ${ }^{3}$ Department of Medicine, Yong Loo Lin School of Medicine, National University of Singapore, Singapore, Singapore

Background: Axial spondyloarthritis $(\mathrm{AxSpA})$ and rheumatoid arthritis $(\mathrm{RA})$ are two common rheumatic diseases that can result in joint damage and deformities, leading to reduced physical function and quality of life. Physical activity (PA) and exercise have been shown to improve general well-being and reduce cardiovascular risk in patients with AxSpA and RA, and are part of the non-pharmacological management in the EULAR guidelines. Despite this, PA levels are reduced in $\mathrm{AxSpA}$ and RA patients ${ }^{1,2}$. In addition, it has also been reported that Asians have lower levels of $\mathrm{PA}^{3}$.

Objectives: This study aims to examine the patterns of PA in a multi-ethnic Asian cohort.

Methods: This was a cross-sectional study conducted between May 2016 and Jan 2017. Consecutive patients with AxSpA and RA were recruited at an outpatient rheumatology clinic at Singapore General Hospital, the largest tertiary hospital in Singapore. Controls were based on a previous cross-sectional study ${ }^{4}$. PA was assessed using the Global Physical Activity Questionnaires (GPAQ) developed by the world health organization $(\mathrm{WHO})^{5}$.

Results: $74 \mathrm{AxSpA}$ and $69 \mathrm{RA}$ patients were recruited and compared to 886 controls. AxSpA patients were younger (median age [IQR], 37.0 [26.3] years) and predominantly male $(75.7 \%)$, while RA patients were the oldest (median age [IQR], 59.0 [16.5] years) and predominantly female (81.2\%). BMI was similar between all three groups. RA patients had more comorbidities (such as hypertension, hyperlipidemia, diabetes mellitus) compared to AxSpA patients and controls.

All three groups had similar proportion of participants meeting $\mathrm{WHO}$ recommendations for $\mathrm{PA}(\mathrm{AxSpA}=77.0 \%, \mathrm{RA}=79.7 \%$, controls $=83.1 \%, \mathrm{p}=0.35)$ and median (IQR) time $(95 \% \mathrm{CI})$ of PA per day [60 (107.1) vs 57.9 (122.9) vs 51.4 (94.3), $p=0.93$ ). More AxSpA patients had a high level of sedentary activity compared to $\mathrm{RA}$ or controls $(\mathrm{AxSpA}=56.8 \%, \mathrm{RA}=23.2 \%$, controls $=7.2 \%, \mathrm{p}$ $<0.01)$. When comparing AxSpA and RA patients with inactive disease or in remission versus active disease, levels of PA did not differ between the 2 groups $(p=0.33)$.

Conclusion: Levels of PA did not differ significant between AxSpA and RA patients compared to the general population, and disease activity levels did not affect the level of PA in patients with AxSpA and RA. Of note was that patients with AxSpA and RA demonstrated higher levels of sedentary activity compared to the general population. Improving PA and decreasing sedentary activity could reduce the cardiovascular risk, especially in patients with $R A$.

References:

[1] Summers G, Booth A, Brooke-Wavell K, Barami T, Clemes S. <p>Physical activity and sedentary behavior in women with rheumatoid arthritis: a comparison of patients with low and high disease activity and healthy controls $</ p>$. Open Access Rheumatol Res Rev. 2019; Volume 11:133-142. doi:10.2147/oarr.s203511

[2] Sundstrom B, Ekergård $H$, Sundelin $G$. Exercise habits among patients with ankylosing spondylitis. Scand J Rheumatol. 2002;31(3):163-167. doi:10.1080/rhe.31.3.163.167

[3] Lip GY, Luscombe C, McCarry M, Malik I, Beevers G. Ethnic differences in public health awareness, health perceptions and physical exercise: implications for heart disease prevention. Ethn Health. 1996;1(1):47-53. doi:10.1080 /13557858.1996.9961769

[4] Win AM, Yen LW, Tan KH, Lim RBT, Chia KS, Mueller-Riemenschneider F. Patterns of physical activity and sedentary behavior in a representative sample of a multi-ethnic South-East Asian population: A cross-sectional study. BMC Public Health. 2015;15(1):1-11. doi:10.1186/s12889-015-1668-7

[5] Bull FC, Maslin TS, Armstrong T. Global physical activity questionnaire (GPAQ): Nine country reliability and validity study. J Phys Act Heal. 2009;6(6):790-804. doi:10.1123/jpah.6.6.790

Disclosure of Interests: Andrew Khor: None declared, Chin Teck Ng: None declared, Warren Fong Consultant of: Abbvie, Janssen, Novartis, Speakers bureau: Abbvie, Janssen, Novartis

DOI: 10.1136/annrheumdis-2020-eular.3229

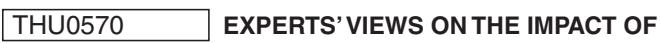 REHABILITATION FOR PATIENTS WITH RHEUMATOID ARTHRITIS IN AUSTRIA}

C. Oppenauer ${ }^{1}$, E. Böttcher ${ }^{2}$, G. Eberl ${ }^{3}$, A. Falkenbach ${ }^{4}$, W. Habelsberger ${ }^{5}$, J. Kirchheimer ${ }^{6}$, W. Kullich ${ }^{7}$, E. Mur ${ }^{8}$, C. Oliveira-Sittenthaler ${ }^{9}$, G. Stummvoll ${ }^{10}$, C. Wiederer ${ }^{11}$, H. Zeindler ${ }^{12}$, V. Nell-Duxneuner ${ }^{13} .{ }^{1}$ Medical University of Vienna, Institute for Outcomes Research, Vienna, Austria; ${ }^{2}$ Humanomed Zentrum Althofen, Althofen, Austria; ${ }^{3}$ Kurzentrum Ludwigstorff Ges.mbH \& Co KG, Bad Deutsch-Altenburg, Austria; ${ }^{4}$ Rehabilitationszentrum Bad Ischl, Bad Ischl, Austria; ${ }^{5}$ Franziskus Spital, Wien, Austria; ${ }^{6}$ Thermenresort Warmbad Villach, Villach, Austria: ${ }^{7}$ Ludwig Boltzmann Department for Rehabilitation, Saalfelden, Austria; ${ }^{8}$ Das Allgemeine öffentliche Landeskrankenhaus InnsbruckUniversitätsklinik, Institit für Physikalische Medizin und Rehabilitation, Innsbruck, Austria; ${ }^{9}$ SKA der PVA Laab im Walde, Laab im Walde, Austria; ${ }^{10}$ Malcherhof Baden, Baden, Austria; ${ }^{11}$ Klinikum am Kurpark Baden, Baden, Austria; ${ }^{12}$ Klinikum Bad Gastein, Bad Gastein, Austria; ${ }^{13}$ Österreichische Gesundheitskasse - Klinikum Peterhof Baden, Baden, Austria

Background: Rehabilitation methods and standards for patients with rheumatoid arthritis (RA) have significantly changed due to more efficient medication improving the course of the disease. Therefore, physical activity, participation, disease management and patient education are most important goals in rehabilitation of patients with RA.

Objectives: Aim of this study was to evaluate the significance and impact of rehabilitation methods according to the subjective attitudes and views of experts and professionals in the field of RA. Opinions of members of the task force (TF) "Rehabilitation" of the Austrian Society of Rheumatology (ÖGR) were compared to the estimation of the other members of the ÖGR.

Methods: All members of the ÖGR were invited to participate in an online survey to rate the impact of rehabilitation for patients with RA between 0 (no impact) and 10 (high impact). Besides sociodemographic and experience related data about the experts and professionals, two main issues were investigated: (1) Impact of rehabilitation related to specific interventions (2) Impact of rehabilitation methods for patients with RA according to different disease and treatment points.

Results: 129 members (50\% male, 50\% female) of the ÖGR participated in the online survey. 12 persons were members of the TF "Rehabilitation" of the ÖGR $11(8.6 \%)$ respondents were general physicians, 66 (51.6\%) specialists in internal medicine with further expertise in rheumatology, $15(11.5 \%)$ specialists in internal medicine, $14(10.9 \%)$ specialists for physical medicine with further expertise in rheumatology, $2(1.6 \%)$ specialists in orthopaedics, $13(10.2 \%)$ health professionals and 7 (5.5\%) persons were from other profession categories such as researchers for example. The majority of respondents $(80 \%)$ worked already 